\title{
A FICÇÃo FREUdiANA. NOTA INTRODUTÓRIA ${ }^{467}$
}

\author{
FABIO HERRMANN
}

O fato inegável é que existe uma flagrante desproporção entre a obra de Freud e a nossa, a obra reunida de todos os psicanalistas que o sucederam. A maior parte da psicanálise encontra-se em Freud, mesmo depois de contar nossa disciplina já uns cem anos de existência, mesmo depois de 55 anos de sua morte.

Não constitui o cerne do problema ser o pensamento freudiano uma referência obrigatória. Isso se passa em extensão semelhante nas ciências naturais com respeito aos autores das mais importantes teorias - ocorre nas matemáticas, onde as demonstrações de Euclides ainda são repetidas após milênios ou onde o nome de Cantor reaparece em cada novo tratado, como talvez nunca deixe de ocorrer com a física de Newton ou de Einstein ou em relação à sociologia weberiana, por exemplo. $O$ verdadeiro desafio não reside em superar e muito menos em esquecer Freud na psicanálise. Superá-lo a ponto de tornar prescindível a leitura atenta de seus escritos não faz sentido; esquecê-lo é fácil, não o nome, é claro, mas a essência de sua obra: basta aderir a uma escola ou praticar uma clínica intuitiva e leviana, para conseguir destacar do nome a substância de seu pensamento.

O problema só se mostra claramente quando refletimos sobre a natureza heurística da desproporção. A maior parte das descobertas psicanalíticas realizadas no campo da alma humana ainda são as de Freud, numa relação talvez de dez para um a seu favor sobre o conjunto da obra combinada de milhares e milhares de analistas que o sucederam. Como pode isso explicar-se? Haverá alguma analogia válida noutros campos de conhecimento?

Um caso comparável poderia ser o de Marx. Sua concepção da vida social produziu notável corrente de sucessores, bem como uma reviravolta no pensamento sociológico e político; contudo, tanto quanto um leigo pode julgar exteriormente, nenhuma obra posterior pôde desenvolver definitivamente o método dialético para além dos limites originais. Aparentemente o marxismo permanece como um sistema capaz de nutrir qualquer intelectual que a ele se dirija e não como uma ciência em que se possam criar teorias de pequena ou grande magnitude, sobre o solo comum de alguns cânones básicos, universalmente aceitos. Há diferenças entre um sistema e uma ciência, talvez a mais simples seja o grau de liberdade que esta última confere ao pesquisador: a ciência é uma espécie de utópica democracia intelectual, em que os princípios gerais ficam registrados naquilo que corresponderia à Constituição de um Estado democrático - respeitando-os, o cidadão fica livre para buscar seu próprio caminho.

Em comum com o marxismo, tem a situação da psicanálise a dificuldade de seu método, sobretudo a dificuldade de isolar método, teorias e prática. Em sã consciência, ninguém pensaria em confundir o método da física com a Teoria da Relatividade nem muito menos em confundi-lo com determinada pesquisa no campo do eletro-magnetismo. Cada teoria ou pesquisa encarna o método de sua respectiva disciplina de maneira particular, porém não há equívoco possível entre o procedimento geral metodológico de uma ciência e qualquer das realizações particulares que nele se modelam. No caso do marxismo e da psicanálise, contrariamente, fica quase impossível imaginar derivados metodológicos que recusem teorias gerais, como as de luta de classes ou do complexo de Édipo, e que, não obstante, permaneçam como exemplos válidos e aceitos da produção intelectual de seu próprio domínio. Já uma teoria que desafiasse o segundo princípio da termodinâmica, embora quase certamente

\footnotetext{
${ }^{467}$ Este texto inédito, ampliado e modificado, compõe o primeiro capítulo do livro A infância de Adão e outras ficções freudianas, São Paulo, Casa do Psicólogo, 2002.
} 
trouxesse descrédito para o autor, nunca deixaria de ser considerada como física, tendo, ao menos por hipótese, o direito de fundar um campo novo dentro daquela ciência.

Talvez seja conveniente comparar a relação que medeia entre a obra de Freud e a de seus sucessores, ao vínculo tão problemático vigente entre uma importante obra literária e a literatura posterior que nela se inspirou. Certo estilo, seja lá o que isso signifique precisamente em cada caso, passa da grande obra para as menores, certa temática, certa preferência pela concisão ou pelas digressões, um acento maior na reflexão ou na emoção etc. Em suma, não é possível realmente dizer o que aparenta um escritor às influências que o construíram e dirigem, embora rios de tinta se tenham vertido sobre esse assunto. É que, na literatura, o método não se destaca com clareza de suas realizações concretas, exatamente como na psicanálise e no marxismo.

Da mesma forma em que um escritor eminente deixa imitadores em seu rasto, mas só encontra pares nos autores de obras de estatura semelhante, fundadoras de outros campos de influência, a obra de Freud domina o campo psicanalítico e, dentro dele, os grandes fundadores de escolas teóricas influenciam-se reciprocamente, todavia não se continuam nem se acrescentam diretamente. E, tal como no marxismo, somos ou não psicanalistas, segundo o grau de nossa adesão aos postulados freudianos. Fora da temática legada por Freud não parece ser admissível produzir psicanálise. Para tanto, seria indispensável separar o método da psicanálise da prática e das teorias, para utilizá-lo onde quer que nos apetecesse.

Depois de ter dedicado o conjunto de Andaimes do real ao ensaio de um resgate do método psicanalítico, com resultados que ainda é cedo julgar, já que se trata de um desses escritos mais freqüentemente mencionados que lidos, gostaria de aproximar-me do problema em pauta, ou seja, a desproporção da obra freudiana sobre a nossa, de forma mais simples. Qual a raiz de nossa dificuldade em continuar dignamente a obra de Freud, isto é, expandi-la a outros domínios temáticos, infirmar certas conclusões ou corrigi-las, propor teorias mais gerais que tomem as suas como casos particulares e assim por diante, como noutras ciências se dá? Em Andaimes do real, sustento a seguinte hipótese. Não é verdade que a psicanálise não possa ser, por sua natureza mesma, uma ciência; decerto, ela só o é potencialmente e o aspecto da ciência, da qual a psicanálise existente faria parte, seria de molde a surpreender profundamente o analista praticante de hoje. No tocante a isso, meu ponto de vista então expresso mantém certa analogia com a idéia althusseriana de ser a nossa uma "teoria regional", a que falta a correspondente "teoria geral". Entretanto, não prefiguro a constituição de uma teoria geral do discurso, na trilha daquele autor, mas a de uma psicanálise metodologicamente generalizada, à qual busco aproximar-me por meio de exemplos concretos.

No momento, gostaria de convidar o leitor a acercar-se ao problema da desproporção de forma radicalmente diversa, abandonando por certo tempo o reino abstrato das definições metodológicas, em troca de uma questão mais particular e, quem sabe, circunstancial. Que tinha Freud que nós não temos? Gostamos todos de referir-nos a Freud como a um gênio - e com certeza ele o foi -; todavia, não é preciso ser um gênio para continuar e problematizar a obra alheia genial. Deixemos também de lado algumas idéias argutas, mas inconclusivas, como a de sua posição de fundador, de pai da horda psicanalítica, ou a de uma transferência insolúvel. São formas de eludir o problema, não de resolvê-lo, fazendo com que a psicanálise se dobre sobre si mesma, a fim de justificar, paradoxalmente, sua impossibilidade de progresso efetivo. O fato é que todos nós fazemos o que Freud fazia, ou pelo menos o que ele dizia que devíamos fazer. Escutamos nossos clientes, às vezes os curamos, tentamos teorizar nossa experiência, lemos, estudamos, pensamos e escrevemos.

Talvez aí resida uma primeira pista. Todos escrevemos; Freud, contudo, escrevia sem parar. São dezenas de milhares de cartas, esboços de artigos, livros, rabiscos, pensamentos no papel. Fora da área da literatura será difícil encontrar alguém que haja escrito tanto quanto Freud. (Marx, a propósito, era também um escritor feroz.) Que faz um escritor de ficção? À 
força de tanto escrever, desenvolve um pensamento pela escrita que cria certo mundo com regras coerentes, um mundo literário onde o mundo real se espelha nalguma de suas características, não porque o autor simplesmente o tente descrever, mas porque este cria um simulacro, um símile, mas tão completo e tão auto-suficiente, que o real não tem melhor remédio que penetrá-lo, deixando-se apreender numa de suas infinitas dimensões.

Essa última sentença, de aparência óbvia, contém duas afirmações, que devem ser apreciadas separadamente no caso de Freud. A primeira é que há um "pensamento por escrito", próprio da literatura. A organização linear do texto, o emprego de metáforas, comparações e de cenas elucidativas para a apresentação das personagens, a transformação de idéias em enredo e a subseqüente reprodução das situações por meio da narrativa, onde tempo, espaço e atributos do ser mimetizam-se no espaço-tempo textual, no colorido sonoro e visual das frases, tudo isso determina uma forma muito especial de pensamento. Escrevendo obcecadamente, Freud pensava por escrito, exatamente como um ficcionista. Em seu esforço para encontrar a expressão justa para a vida psíquica, fica evidente uma seleção do material a ser comunicado e uma modelagem conceitual operada pelo instrumento de comunicação. Idéias abstratas, assim como situações clínicas, vão sendo escolhidas e ordenadas sob o império das necessidades inerentes ao texto. Numa palavra, não é tudo que se pode dizer, ou melhor, pensar por escrito.

A composição arquitetônica do aparelho psíquico que ideou, tanto na primeira quanto na segunda tópicas, é singularmente propícia à expressão literária. São lugares em oposição, sujeitos-personagens habitam-nos e interagem, relacionam-se como mecanismos de defesa ou imagos inconscientes, obedecendo a regras tão estritas como as que regem um conto de fadas, onde cada gesto possui sempre significado e conseqüências ineludíveis. Os historiais clínicos são, aqui, história de amor, lá, conto detetivesco. Não é possível acreditar em simples coincidência: seria impossível para Freud trabalhar de uma maneira e escrever de outra, e ainda menos possível que, por acaso, sua decifração dos sintomas de Dora, para ficarmos na história de amor, desembocasse exatamente numa lógica tão perfeitamente literária e apta à narrativa. Freud devia tratar como escrevia, como um literato. Os diálogos que dele nos chegaram parecem muitas vezes extraídos de um romance ou de uma peça de teatro. ${ }^{468}$ Não creio que se esteja cometendo qualquer abuso interpretativo ao julgar que Freud transformou sua própria vida em obra literária, como se vivesse uma autobiografia contínua. Seus gestos pessoais parecem estudados para ter efeito estético; a política que montou para o movimento psicanalítico semelha um romance histórico: o círculo secreto, os anéis, os complicadíssimos complôs para alçar ou afastar certos discípulos. No fundo, Freud inventou o mundo anímico como quem escreve um romance, mas habitou-o como se fora uma personagem.

Imaginemo-nos a entrar em seu consultório, na Berggasse 19, em qualquer dia, neste começo de século. Há um pouco do consultório médico da época, menos frio que os de hoje, porém acrescentado de sugestões discrepantes. Muitos livros, em primeiro lugar, indicando a presença de um sábio ou pensador. Depois, a coleção de antigüidades egípcias, etruscas e gregas, criando a impressão de estarmos diante de uma testemunha dos tempos, capaz de compreender a essência profunda da história humana. Dele já saberíamos, aliás, alguma coisa: que se considera capaz de traduzir a psique, que estudou e compreendeu o enigma dos sonhos, que investigou algumas grandes figuras históricas, mitos e religiões. Um homem imerso nos mistérios. O Egito estava na moda então; acreditava-se ser o berço de um saber esotérico, que os esoterismos da época procuravam imitar a qualquer preço: pendurado sobre o divã, lá vemos uma reprodução das colossais estátuas de Ramsés II, talhadas na rocha viva do templo de Abu-Simbel. O próprio divã, coberto de tapetes orientais, vistoso, imponente, esconde a

\footnotetext{
${ }^{468}$ Veja-se, por exemplo, a descrição da consulta feita a Freud por um jovem poeta, Bruno Goetz, ao fim da qual Freud teria entregue um envelope contendo duzentas coroas, como "honorários pelo prazer que os versos e a história do poeta lhe haviam proporcionado" ("Aspectos Literários em Freud", in Marialzira Perestrello, Encontros: psicanálise \&, Rio de Janeiro, Imago, 1992, p. 45 ss).
} 
poltrona onde se deveria sentar o professor, convidando-nos a recostar-nos. Nessa atmosfera prenhe de sugestões penumbrosas, talvez fôssemos de imediato levados a falar de sonhos, talvez nos queixássemos dos sintomas de uma neurose, ou de idéias recorrentes e incompreensíveis. Ele, contudo, haveria de atalhar-nos com perguntas precisas, exigindo detalhes e explicações, para, enfim, fornecer alguma explicação bastante lógica e rigorosa. $\mathrm{Ou}$ seja, num ambiente convidativo ao devaneio, Freud assumiria a função da consciência sem se fazer rogar. Mas, deitados, não lhe poderíamos replicar num diálogo de consciências simétricas, cabendo-nos, por conseguinte, o resto, o outro lado, aquilo que ainda não existia no imaginário comum, mas que estava sendo ali introduzido: seríamos convertidos em inconsciente. Uma cena, uma bela e eficiente cena teatral, sem sombra de dúvidas.

Isso significa que tanto a técnica terapêutica quanto a teoria psicanalítica possuem a forma geral de uma ficção literária? Neste ponto, é preciso ser cauteloso; não devemos subestimar nem superestimar os efeitos de ficção na origem da psicanálise. Um erro comum é concluir apressadamente que, sendo ficção, a psicanálise carece de realidade, ou que, sendo literatura, deixa de ser ciência. A ciência moderna comporta duas dimensões solidárias, mas às vezes antagônicas. É descoberta de fatos novos e de novas ligações entre eles; a ciência produz teorias explicativas e propõe novos instrumentos de intervenção na realidade, que nelas se baseiam - até aqui, estamos na área dita heurística, certamente a mais importante para qualquer ciência. Todavia, as ciências possuem igualmente uma função complementar da sua vocação heurística, consistente nas operações de filtro pelas quais os achados se comprovam. Este apêndice, a comprovação, é tão importante nas ciências modernas, nas quais se teme sobretudo a possibilidade de falsificações involuntárias de dados e conclusões, que, hoje, temos todos a tendência a definir o conhecimento científico, não por sua produtividade, mas pelos critérios de validação da experiência. Esta inversão de prioridade afeta de tal modo o saber moderno, que chega a acorrentá-lo aos modos tradicionais, às disciplinas estabelecidas, à física, paradigmaticamente, sem permitir o aparecimento de formas novas de aproximação à realidade. E é aí que entra a ficção. Ela goza de certa autonomia com respeito ao dever de comprovação, adia-o pelo menos - da literatura não se espera comprovação de espécie alguma, do momento ficcional de uma hipótese de trabalho, espera-se que seus frutos posteriores possam ser provados. Assim, na raiz da psicanálise, sua dimensão ficcional liberou o potencial heurístico, justificativa de uma nova forma de ciência, desagrilhoando-o dos ferros da necessidade de comprovação precoce.

Por outro lado, podemos subestimar os efeitos da forma literária e do espírito ficcional, ao crer que são estes apenas um modo ou estilo próprio da expressão freudiana. Nada mais longe da verdade, creio. Como vimos, o pensamento por escrito, o anseio de plena expressão em forma literária, afeta os modos de produção e não somente os de expressão de nosso conhecimento. Quem sabe, resida aí uma das dificuldades para a continuação da obra de Freud pelos analistas. Tal como ele, mais até que ele, somos personagens dessa história, e não cabe à personagem reinventar o enredo de que faz parte. Dentro da ficção do aparelho psíquico (eine theoretische Fiktion, chama-o Freud na Traumdeutung), por exemplo, o analista não está livre para questionar a existência do inconsciente, uma vez que sua constituição mesma como analista depende dessa crença. Num plano mais modesto, o analista que põe em dúvida os efeitos especiais de transferência, considerados ubíquos por seu próprio grupo escolástico, é tratado simplesmente como um incapaz, assim como o seria o ator que não tivesse entrado completamente no espírito da peça em que atua. Ora, pode ser que o único caminho para conseguirmos ampla liberdade criativa dentro da psicanálise seja o de repetir o gesto freudiano que privilegia a ficção heurística contra a prisão acadêmica, só que agora no interior do corpo teórico a que pertencemos.

Em resumo, abrem-se dois caminhos diante de nós para superar a relativa paralisia em que nos encontramos face à tarefa que a psicanálise nos solicita, a de fazer avançar decisivamente o conhecimento da alma humana. Consiste o primeiro - talvez o mais 
fundamental e frutífero - em decantar cuidadosamente da solução psicanalítica as partículas de reificação conceitual que nela flutuam, assim como as particularidades técnicas e as preferências teóricas dos diferentes autores, de forma a recuperar o fluido metodológico em estado puro, ou seja, a operação essencial que produz saber e cura no reino do psiquismo. Esse procedimento, a eliminação de impurezas, leva-nos apenas até o umbral de novas criações, pois desemboca numa crítica da teoria e da prática, região onde se tornam demasiado abstratos seus resultados para inventar novos exemplos concretos. O segundo caminho dá resultados mais imediatos e, de certa forma, complementa o primeiro. Tomando em consideração os efeitos ficcionais contidos na teoria e na clínica psicanalíticas, estabelecemos ao redor de nós um campo de ceticismo heurístico. Equivale a dizer que não precisamos crer cegamente no sistema inteiro de pressupostos e concepções psicanalíticas, sem que por isso tenhamos que demoli-lo ou afastar-nos dele. Podemos, portanto, criar novas teorias, desde que, é lógico, resistamos à tentação de considerar estas últimas como mais verdadeiras que as anteriores, mas simplesmente como novas ficções teóricas à espera de comprovação metodológica. $\mathrm{O}$ mesmo princípio cético que nos libera, protege-nos também contra nós mesmos. Fica, pois, evidente para o analista que aceita este pacto de dúvida construtiva uma espécie de descontinuidade entre o caminho metodológico e o ficcional: o campo de ceticismo protetor ocupa justamente o lugar de uma análise suficientemente rigorosa do método psicanalítico que permitisse integrar harmoniosamente pesquisa, teorização e clínica, numa produção científica contínua.

Antes de encerrar este breve comentário introdutório, gostaria de deixar registradas duas hipóteses provisórias e bastante limitadas a respeito dos resultados possíveis do trabalho com a ficção psicanalítica. O primeiro exemplo resume-se a ser uma tentativa de reconhecimento do corpo a que pertencemos, já que temos a ambição de sermos livres em seu interior, e não a de nos desembaraçarmos dele. O segundo refere-se à atmosfera ideológica, por assim dizer, que domina nossa concepção do homem e a uma variante possível dessa concepção.

O domínio de direito da psicanálise é a vida psíquica do homem, como é evidente. Entretanto, como é também evidente quando se acompanha a produção psicanalítica contemporânea, nossa disciplina cobre seu domínio de maneira muito especial e circunscrevese a certos temas particulares. No dia-a-dia de nossas discussões, só reconhecemos como psicanalítico um argumento que aborde a temática freudiana: ainda não se deu o processo de abstração e redeterminação que poderia fazer de todo ato psíquico tema da psicanálise. Ao discutir os sonhos, começamos sistematicamente pelo da Injeção aplicada em Irma, quase nenhum estudo sobre atos falhos prescinde da reanálise do Signorelli, a neurose é Dora ou o Homem dos ratos, a psicose Schreber etc. Para algum observador de fora pareceria até surpreendente que um analista possa ainda ter a esperança de encontrar algo de novo nessas referências obrigatórias, nessas estradas de trânsito tão carregado. Mas não é algo de novo o que se procura, e sim a forma psicanalítica, a maneira psicanalítica de pensar. Que isso se deve a uma deficiência na demonstração e isolamento do método psicanalítico, não se pode duvidar. Não obstante, há outra explicação acessória, que nasce desta consideração da psicanálise como ficção freudiana. Dá-se que, nascida da auto-análise de Freud, a psicanálise tem como objeto prático o próprio Freud. Numa palavra, o inconsciente é a psique de Freud desdobrada. Da mesma forma que Homero ou Shakespeare transformaram-se em objeto de disciplinas especiais, a escrita freudiana constituiu-o como campo científico, e este Freud de que falamos constantemente é também, como Hamlet ou Odisseus, uma personagem extensa, um exemplo paradigmático do humano. Os processos psico-primários são a forma mental da personagem que sonha os sonhos da Traumdeutung, nossa clínica está apoiada nas quatro personagens psicanalíticas principais e numas quantas secundárias. Isso não impugna, sem dúvida, a solidez empírica da psicanálise, porém abre caminho para que a retomemos ficcionalmente, para que criemos outras ficções teóricas que aos poucos se possam desgarrar 
da experiência original, sem negá-la, sem esquecê-la, mas recriando-a com outros matizes e noutros campos.

A segunda questão, ideológica, poderia ser assim esboçada. O homem freudiano (não o Homem Psicanalítico, esse reflexo ontológico do método da Psicanálise) tem como característica central o entrejogo de forças psíquicas, fundamentalmente da libido, que pode vir a carregar alguma representação do mundo, do outro humano antes de mais nada. $\mathrm{Na}$ concepção ideológica gerada pela prática comum dos analistas, é como se cada homem estivesse ocupado em suas coisas internas, sendo a consciência uma observadora dos movimentos anímicos. Por isso se diz com tanta freqüência que o importante não é o que ocorre, senão a forma pela qual alguém vive isso ou aquilo, que o que conta é a emoção ou a experiência interna. A impressão geral é que esses homens vivem num diálogo permanente com suas figuras internas, diálogo que, por vezes, alcança o outro, também ocupado num solilóquio infindável e inconsciente. Nesse mundo, a intenção vale mais que o ato, os sentimentos mais que as idéias. Nem seria preciso dizer que tal posição mutila o pensamento freudiano. Não é coisa de suas teorias necessariamente, embora apóie-se em aspectos marginais da personagem, por assim dizer. Não é verdade que, quando da ruptura com Jung, escreve Freud a Binswanger: "retirei dele a minha libido e agora ele já não me faz falta nenhuma [...] tenho agora postos disponíveis para você, Ferenczi, Rank, Sachs, Abraham, Jones, Brill e outros"? ${ }^{469}$ Esses deslocamentos objetais da libido, essa energética oportunista que tira de um para pôr no outro, foi convertida em regra geral na ficção psicanalítica. Em sua melhor versão produz efeitos interessantes. Transformamo-nos em personagens com uma vida interior quase aleatória, flutuando ao sabor de determinações extra-conscientes, às vezes infantis, às vezes lingüísticas, mas sempre peremptórias e irrevogáveis. Uma história de surdos-mudos, ou mais precisamente de solipsistas psíquicos, cujo encontro apenas se dá como reflexo da mecânica das representações inconscientes. Numa palavra: somos inteiramente modernos nesse ponto.

Contudo, nada impede que criemos ficções diferentes. Uma variante possível - não a única com certeza, mas esta pelo menos bastante ortodoxa - seria contar a mesma história assim. Os homens vivem imersos em suas relações. Sua vida psíquica efetivamente se volta para o exterior, para os outros, não só como percepção e ato, mas também como memória, emoção e fantasia. Todavia, a relação com os outros homens possui significações complexas e muito pouco delas pode se fazer consciente num dado momento. Antes, sendo a realidade múltipla, havendo realidades plurais, agora suspeitamos de um grande complô de nossos amigos para, no instante seguinte, estarmos seguros de sua amizade, por exemplo. Então, nesse novo momento, caso subsista alguma memória da atitude anterior, ela nos parece singularmente estranha, inexplicável, e procuramos encontrar suas causas, não raro atribuindo-as a alguém - ou seja, retornamos à primeira hipótese, porém de forma circunscrita. Ora, cada um desses campos determinantes da forma da realidade generalizadamente persecutória, depois amistosa, em seguida circunscritamente persecutória, mas explicável por argumentos inventados ad hoc - contém certas regras de relação que podem ser expressas teoricamente. A psicanálise procura organizar essas regras num conjunto solidário e racional; quando se trata de exprimir o saber psicológico já adquirido sobre campos conhecidos, é permissível pois falar metaforicamente num aparelho psíquico dotado de certas propriedades gerais, aquelas dos campos descritos; quando, entretanto, desejamos explorar novos campos, não há melhor maneira que partir de uma história: quer seja a de um paciente ou a de uma personagem fictícia. A ficção, apreendendo o estofo psíquico da vida de relações, isola o campo a ser investigado, purifica-o da complexidade infinita de outras intromissões do real e, por fim, recria as condições para nova teorização. Pela ficção, talvez

${ }^{469}$ Citado em L. Flem, O homem Freud, s. 1.: Campus, p. 253. 
possamos voltar à teoria produtivamente - entendendo por produtivo o pensamento que gera saber sobre novo campo da vida anímica.

Ao reconsiderar a psicanálise por meio dos efeitos de ficção que comporta, cubrimonos com um campo de ceticismo protetor. Dentro dele, perde dogmatismo nossa teoria, tornase fluida e móvel, adequada à reinvenção. Novamente podemos teorizar a partir da origem, tal como Freud o fez. Apenas é necessário um cuidado final. O ceticismo só é curativo quando se usa em doses moderadas e num ponto médio de influência. $\mathrm{O}$ ceticismo extremo leva o sujeito a descrer tanto de seu conhecimento anterior que, à míngua de suporte epistemológico, acaba por crer em qualquer outra coisa diversa: o que, no caso da psicanálise, seria um erro irreparável. 